\title{
Changes in the Regulatory Effects of Cell-Cell Interactions on Neuronal AChR Subunit Transcript Levels after Synapse Formation
}

\author{
Marjory S. Levey and Michele H. Jacob \\ Worcester Foundation for Biomedical Research, Shrewsbury, Massachusetts 01545
}

Nicotinic acetylcholine receptors (AChRs) mediate excitatory synaptic transmission in the chick ciliary ganglion. AChR protein and mRNA levels are increased by both innervation and retrograde signals from target tissues during synapse formation. We now show that $\operatorname{AChR~} \alpha 3, \beta 4$, and $\alpha 5$ subunit transcript levels stop increasing after synaptogenesis. Moreover, maintenance of these mRNA levels requires the continued presence of regulatory signals from both pre- and postganglionic tissues. Unilateral preganglionic denervation or postganglionic axotomy causes declines in $\alpha 3, \beta 4$, and $\alpha 5$ transcript levels, ranging from twofold to 3.5-fold, relative to contralateral control neuron values in newly hatched chicks. The reductions are not merely an injury response; $c \beta 4$-tubulin mRNA levels are not affected by either axotomy or denervation. Further, similar decreases in AChR mRNA levels are observed after local application of colchicine to the postganglionic nerves, which blocks fast transport without disturbing axonal integrity. These results also demonstrate a developmental change in the regulatory effects of target tissues. Reductions in $\alpha 5$ mRNA levels caused by axotomy or colchicine treatment after peripheral synapse formation contrast with the lack of an effect on $\alpha 5$ when synapse formation with the target tissue is prevented. The ability of the target tissue to regulate $\alpha 5$ mRNA levels after synaptogenesis is interesting, because this subunit may be necessary for the formation of high-conductance AChRs. The specific regulatory effects of target tissues and inputs at different developmental stages demonstrate that neurons continually depend on signals from their pre- and postsynaptic tissues to accomplish mature levels of AChR subunit expression and optimal functioning of that neuronal circuit.

Key words: nicotinic acetylcholine receptors (AChRs); parasympathetic ciliary ganglion neurons; development; synapse formation and maturation; denervation; axotomy; regulation of gene expression; $m R N A$
Although nervous system function depends on synaptic communication, the cellular and molecular mechanisms that regulate neuronal synapse formation and maintenance are largely undefined. Neurons engage in two distinct types of synaptic interactions: they receive innervation and form synapses on target tissues. We have shown recently that innervation and target tissues have differential inductive effects on AChR subunit transcript levels in developing neurons during synapse formation (Levey et al., 1995). The present study was undertaken to determine whether similar regulatory interactions control the maintenance of neuronal synapses.

The chick parasympathetic ciliary ganglion (CG) is a uniquely well-suited model for identifying in vivo mechanisms that regulate synapse formation and maintenance, because the synaptic interactions are amenable to experimental manipulation in situ (Jacob and Berg, 1987, 1988; Arenella et al., 1993; Dourado et al., 1994; Levey et al., 1995). AChRs mediate excitatory synaptic transmission in the chick CG (Martin and Pilar, 1963a,b). Neuronal AChRs are pentameric complexes (Anand et al., 1991; Cooper et al., 1991). Subunit analysis of CG AChRs show that they collectively contain $\alpha 3, \beta 4$, and $\alpha 5$ subunits. In addition, a small subpopulation, only $\sim 20 \%$, also contain $\beta 2$ (Conroy and Berg, 1995). Before innervation, few AChRs are detected in CG neurons (Jacob, 1991). AChR expression increases dramatically during

Received May 30, 1996; revised July 31, 1996; accepted Aug. 9, 1996.

This work was supported by grants from National Institutes of Health (NS-21725 to M.H.J.) and the Pfeiffer Foundation (M.H.J.) and a Muscular Dystrophy Association postdoctoral fellowship (M.S.L.).

Correspondence should be addressed to Dr. Michele H. Jacob, Worcester Foundation for Biomedical Research, 222 Maple Avenue, Shrewsbury, MA 01545.

Copyright (C) 1996 Society for Neuroscience $0270-6474 / 96 / 166878-08 \$ 05.00 / 0$ synapse formation (Smith et al., 1985; Jacob, 1991; Corriveau and Berg, 1993). Innervation and target tissues have redundant, as well as unique, inductive effects on AChR mRNA levels (Levey et al., 1995). $\alpha 3$ and $\beta 4$ transcript levels are increased by both presynaptic inputs and target tissues. In contrast, innervation increases $\alpha 5$ mRNA levels, but target tissues have little effect. The abundance of high-conductance AChR channels also increases relative to low-conductance AChRs during synapse formation and maturation (Margiotta and Gurantz, 1989). In vitro expression studies suggest that $\alpha 5$ may be necessary for the formation of high-conductance AChRs (Ramirez-Latorre et al., 1996). Developmental increases in CG $\alpha 5$ mRNA levels relative to the more abundant $\alpha 3$ transcripts suggest that a greater number of AChRs contain $\alpha 5$ at later embryonic stages (Levey et al., 1995). Thus, increases in AChR transcript levels induced by innervation and target tissues may cause changes in AChR number, subunit composition, and functional properties that are likely to increase levels of synaptic activity during the critical period of synapse stabilization and elimination and neuronal cell death.

The present studies extend our knowledge of the regulation of AChR expression at later developmental stages in four ways. First, we show that $\alpha 3, \beta 4$, and $\alpha 5$ transcript levels stop increasing after synapse formation, thus extending previous analyses of AChR mRNA levels in normal developing CGs by including stages before and after synaptogenesis (Corriveau and Berg, 1993). Second, declines in $\alpha 3, \beta 4$, and $\alpha 5$ mRNA levels after axotomy and denervation demonstrate that the maintenance of all three mRNA levels requires the continued presence of both innervation and retrograde signals from the target tissues in mature CG neurons in situ, as established previously only for $\alpha 3$ 
Table 1. Neuronal survival

\begin{tabular}{|c|c|c|c|c|c|c|c|c|}
\hline \multicolumn{3}{|c|}{ Denervation } & \multicolumn{3}{|c|}{ Axotomy } & \multicolumn{3}{|c|}{ Colchicine } \\
\hline & Control & Operated & & Control & Operated & & Control & Treated \\
\hline \multirow[t]{3}{*}{ P10 } & ND & $2390 \pm 210^{a}$ & $\mathrm{P} 1$ & $2382 \pm 54$ & $1983 \pm 98$ & $\mathrm{P} 5^{*}$ & $2268 \pm 92$ & $2201 \pm 53$ \\
\hline & & & P5 & $2370 \pm 250^{a}$ & $1490 \pm 110^{a}$ & & & \\
\hline & & & $\mathrm{P} 5 *$ & $2219 \pm 87$ & $1422 \pm 72$ & & & \\
\hline
\end{tabular}

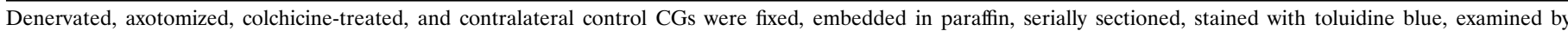

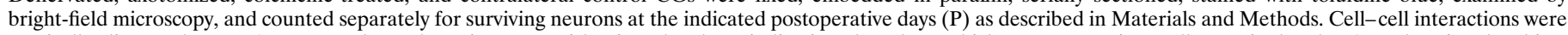

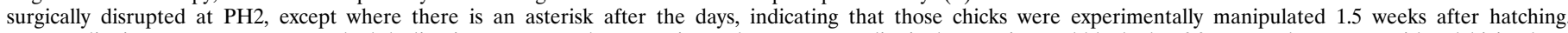

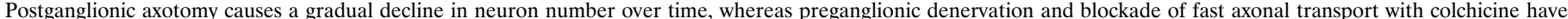

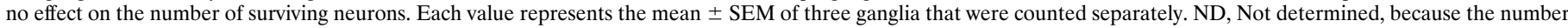
of neurons in contralateral control ganglia is not significantly different at any of the posthatch ages examined, ranging from 3 to $25 \mathrm{~d}$ (Student's $t$ test).

${ }^{a}$ These values were taken from Jacob and Berg (1987).

(Boyd et al., 1988). Third, the specificity of the regulatory response to axotomy, a key concern relevant to all lesion studies, is addressed by demonstrating similar declines in AChR mRNA levels after colchicine treatment of postganglionic nerves. Colchicine blocks fast transport without disturbing axonal integrity (Karlsson and Sjostrand, 1969; Pilar and Landmesser, 1972; Davis, 1990). Fourth, the results demonstrate a developmental change in the ability of the target tissue to regulate $\alpha 5$ mRNA levels after synapse formation. Thus, both input and target tissues play a key role in the induction and maintenance of $\mathrm{AChR}$ expression in neurons.

\section{MATERIALS AND METHODS}

Normal developing ciliary ganglia (CGs). White Leghorn embryonated chick eggs (Spafas, Norwich, CT) were maintained at $37^{\circ} \mathrm{C}$ in a forceddraft turning incubator until use. Embryos were staged according to the Hamburger and Hamilton (1951) classification scheme. CGs were dissected at selected stages of synapse formation and maturation, ranging from embryonic day 4 (E4) to posthatch day 12 (PH12). CGs were frozen immediately in liquid nitrogen and stored at $-80^{\circ} \mathrm{C}$ until use for RT-PCR.

Surgical manipulations. Surgical manipulations to disrupt synaptic connections were performed on CGs in chicks $2 \mathrm{~d}$ after hatching using methods described previously (Jacob and Berg, 1987). For preganglionic denervation, the single input from the accessory oculomotor (EdingerWestphal) nucleus was severed. For postganglionic axotomy, all of the ciliary and choroid nerves emerging from the CG were lesioned. Denervation or axotomy was performed unilaterally, preserving the contralateral ganglion as an intact control. After surgery, chicks were maintained in a heated brooder for 2, 5, or $10 \mathrm{~d}$ after denervation and 1,3 , or $5 \mathrm{~d}$ after axotomy. The total absence of the pupillary light reflex was used as a criterion for a successful operation. The ganglion was also examined during dissection to confirm that the appropriate nerves remained completely severed. The success rate of the surgery was $\sim 95 \%$. Operated and contralateral control ganglia from the same animal were always paired and processed in parallel for RT-PCR or light microscopic analysis.

Colchicine treatment. Local application of colchicine to CG postganglionic nerves was performed using minor modifications of a method described previously (Pilar and Landmesser, 1972). The modifications include the use of $5 \%(\mathrm{w} / \mathrm{v})$, rather than $10-20 \%$, colchicine in PBS and treatment at 1.5 weeks, rather than 1-2 d, after hatching. The modifications enhanced survival; $\sim 85 \%$ of the experimentally manipulated chicks survived. In comparison to the surgery used for denervation and axotomy, colchicine treatment requires the chicks to be anesthetized for a longer time ( $\sim 20$ min compared with $3 \mathrm{~min}$ ), which may compromise survival at the earlier age. Briefly, chicks were anesthetized with methoxyfluorane, and a small incision was made along the caudal portion of the lower eyelid on one side only. The eyeball was gently retracted, and the CG postganglionic nerves were exposed. A small sterile cotton pellet, which had been soaked in 5\% colchicine in PBS and air dried in a sterile dish, was applied unilaterally to a distal portion of the postganglionic nerves for $10 \mathrm{~min}$. The pellet was then removed, and the area was thoroughly rinsed with sterile PBS. The incision along the lower eyelid was sutured, and the chicks were allowed to recover. Controls in which the nerves were treated similarly, but colchicine was omitted from the pellet, had AChR mRNA levels resembling untreated age-matched CGs. To compare the effects of colchicine treatment to those of axotomy, chicks were also axotomized at 1.5 weeks after hatching.

Quantitative RT-PCR. Total RNA was extracted from individual ganglia by the guanidinium isothiocyanate-hot phenol method (Feramisco et al., 1982 ) as modified by the addition of glycogen as carrier. Known concentrations of an $\mathrm{AChR} \alpha 3, \alpha 5, \beta 4$, or $\mathrm{c} \beta 4$-tubulin mutated internal standard, equivalent to the quantity of that transcript present in that ageoperated or control ganglion (as determined initially by competitive RT-PCR), were added to the ganglion at the start of RNA extraction (Levey et al., 1995). The mutated standards resemble the regions of the cellular mRNAs targeted for amplification with the exception of $2 \mathrm{bp}$ changes required to replace an existing restriction endonuclease site with a novel restriction site. Ganglionic RNA and the mutated internal standard cRNA were amplified by quantitative RT-PCR in the presence of $\left[\alpha^{32}\right.$-P]dCTP using forward and reverse primers for $\alpha 3, \alpha 5, \beta 4$, and c $\beta 4$-tubulin, as reported previously (Levey et al., 1995). Restriction enzyme mapping and gel electrophoresis were used to distinguish PCR products derived from the mutated standard and the ganglionic mRNA. Fragments were transferred to a Zeta probe blotting membrane (BioRad, Hercules, CA) and exposed x-ray film. The ratio of the ganglionic mRNA products and the mutated standard products was determined by densitometric scanning (PDI densitometer, Huntington Station, NY) of the resulting autoradiogram.

Neuronal cell counts and morphology. Neuron numbers were counted in axotomized and contralateral control ganglia 1 and $3 \mathrm{~d}$ after surgery and in colchicine-treated ganglia and their contralateral controls after 5 and $15 \mathrm{~d}$. Neuron numbers in ganglia $10 \mathrm{~d}$ after denervation and $5 \mathrm{~d}$ after axotomy and their contralateral controls were taken from Jacob and Berg (1987) (Table 1). Briefly, ganglia were fixed in $4 \%$ paraformaldehyde in PBS, processed for paraffin histology, serially sectioned at $8 \mu \mathrm{m}$, and stained with toluidine blue (Arenella et al., 1993; Levey et al., 1995). All neurons possessing a nucleus with a distinct nucleolus were counted in each section of the ganglion. Cell counts were corrected for double counting by the method of Abercrombie (1946). The same control, axotomized, and colchicine-treated ganglion sections were also used to calculate the percentage of ciliary neurons undergoing chromatolysis. Ciliary neurons in which the Nissl substance was fragmented and dispersed throughout the cytoplasm were considered chromatolytic. Choroid neurons were not evaluated, because axotomy causes no apparent change in the distribution of their normally dispersed individual cisternae of rough endoplasmic reticulum. Ciliary and choroid neurons were distinguished on the basis of differences in their size, shape, and staining intensity of the cytoplasm (Landmesser and Pilar, 1974a).

\section{RESULTS}

\section{AChR subunit mRNA levels increase dramatically during synaptogenesis, and then plateau, in CG neurons developing in situ}

AChR $\alpha 3, \beta 4$, and $\alpha 5$ transcript levels in individual chick CGs were established at selected stages of synapse formation and maturation (Fig. 1). Absolute levels were measured using quan- 


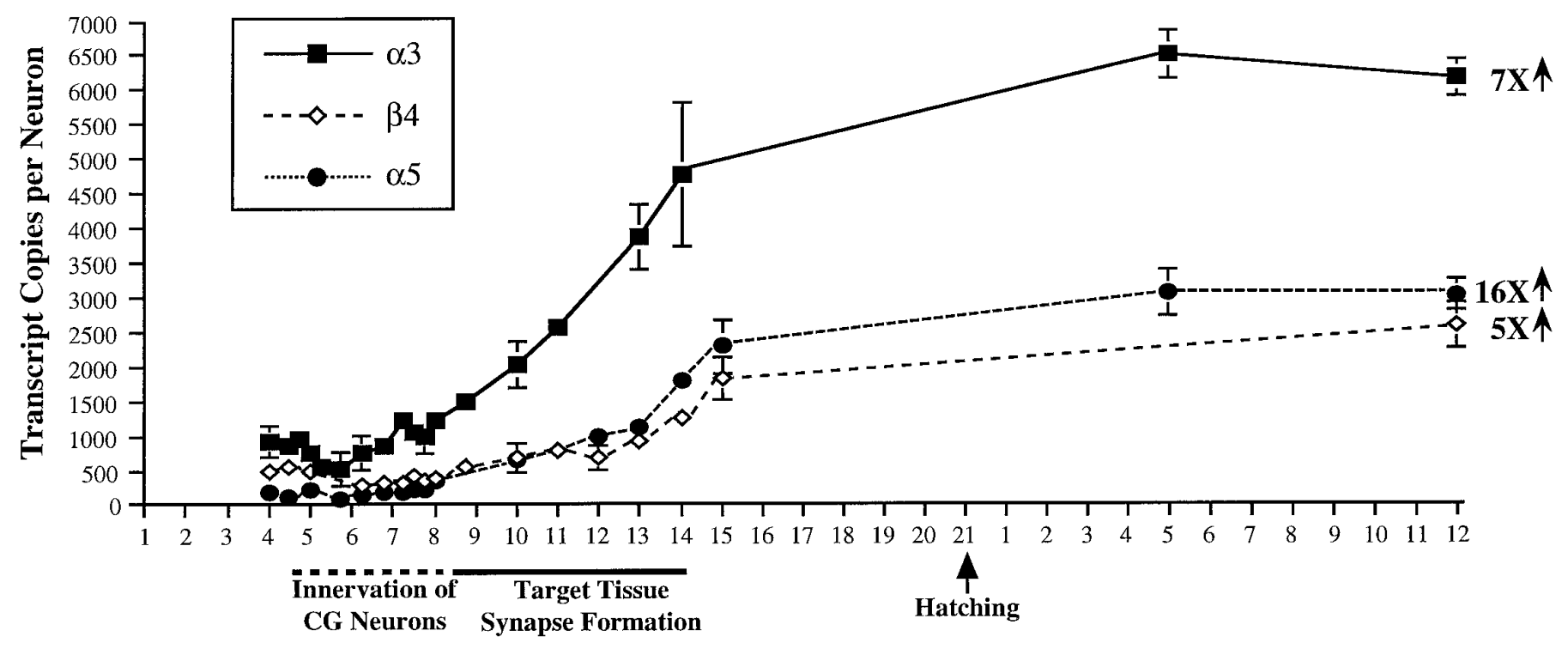

Embryonic and Posthatch Age in Days

Figure 1. AChR $\alpha 3, \beta 4$, and $\alpha 5$ subunit transcript levels increase during pre- and postganglionic synapse formation and then plateau in CG neurons developing in situ. Absolute amounts of $\mathrm{AChR} \alpha 3, \beta 4$, and $\alpha 5$ subunit mRNAs were measured in individual ganglia at selected stages preceding, during, and after synapse formation by using RT-PCR with mutated internal standards. Values are normalized to the number of transcript copies per neuron to account for developmental changes in neuron number. Neuron numbers per ganglion were taken from Landmesser and Pilar (1974b) and Furber et al. (1987). Each value represents the mean \pm SEM of two to eight separate determinations. In cases in which error bars are not visible, they are within the symbol.

titative RT-PCR and known concentrations of a mutated AChR subunit cRNA internal standard (Levey et al., 1995). Data were normalized to transcript copies per neuron to account for developmental changes in CG neuron number (Landmesser and Pilar, 1974b; Furber et al., 1987). Ganglia were sampled at ages ranging from E4 to PH12. E4 precedes innervation, which begins at E4.5 (Jacob, 1991). By E8, functional chemical synapses are present on every neuron (Landmesser and Pilar, 1972). Innervation occurs before target tissue synaptogenesis. From E8.5 to E14, CG neurons establish synapses on their target striated and smooth muscles in the eye (Meriney and Pilar, 1987; Pilar et al., 1987).

Low but detectable levels of $\alpha 3, \beta 4$, and $\alpha 5$ transcripts are present before innervation (Fig. 1). All three transcript levels increase during synapse formation. The greatest rise occurs between E9 and E15, during the time when target tissues are innervated and preganglionic inputs mature in efficacy and morphology, with calyces forming on ciliary neurons (Landmesser and Pilar, 1972). Subsequently, AChR transcript levels are not significantly altered up to PH12, the latest time point examined (Student's $t$ test). Overall, AChR $\alpha 3, \beta 4$, and $\alpha 5$ mRNA levels increase 7-fold, 5-fold, and 16-fold, respectively, during synapse formation and maturation, from E4 to PH12 (Fig. 1). Similar increases in $\alpha 3, \beta 4$, and $\alpha 5$ mRNA levels were reported previously for CGs from E8 to E18, as determined by quantitative RNase protection experiments (Corriveau and Berg, 1993). $\alpha 3$ transcripts are two- to threefold more abundant than $\alpha 5$ and $\beta 4$ mRNAs at all developmental stages examined, except at the earliest stages, when $\alpha 5$ is least abundant, and $\alpha 3$ is present at fivefold higher levels (Fig. 1). In comparison, $\beta 4$ and $\alpha 5$ are present at similar levels. In total, these results suggest that innervation and target tissues both induce increases in AChR subunit mRNAs in CG neurons during synapse formation, after which AChR transcript levels stop increasing.

\section{AChR subunit mRNA levels decline after surgical transection of synaptic connections in the mature CG}

To determine the separate role of innervation and target tissue interactions in maintaining $\operatorname{AChR~} \alpha 3, \beta 4$, and $\alpha 5$ transcript levels in mature $\mathrm{CG}$ neurons, transection of the preganglionic accessory oculomotor nerve (denervation) or postganglionic ciliary and choroid nerves (axotomy) was performed unilaterally in newly hatched chicks. The CG from the unoperated contralateral side served as an internal control.

AChR $\alpha 3, \beta 4$, and $\alpha 5$ subunit mRNA levels decline rapidly after denervation and axotomy (Fig. 2). Reductions in the three transcript levels range from twofold to 3.5 -fold relative to contralateral control neuron values by $10 \mathrm{~d}$ after denervation and $5 \mathrm{~d}$ after axotomy. These times were selected because substantial reductions in AChR protein levels are known to occur by then (Jacob and Berg, 1987). In addition, sampling the CG up to $5 \mathrm{~d}$ after axotomy minimizes any possible contribution of a loss of presynaptic terminals, because axotomy of the chick CG for $9 \mathrm{~d}$, a longer period, reduces the total synaptic contact area on the neurons by only 37\% (Brenner and Johnson, 1976). Transcript levels were normalized to account for decreases in neuron number observed to occur after axotomy but not after denervation (Table 1) (Jacob and Berg, 1987). No compensatory change is detected in AChR mRNA levels in unoperated contralateral CGs from the same animals.

Greater reductions in $\alpha 3$ and $\beta 4$ mRNA levels occur after axotomy compared with denervation (Fig. 2; see also Fig. 5) (Student's $t$ test). In contrast, $\alpha 5$ mRNA levels are decreased to the same extent at matched ages after these manipulations. Declines in $\alpha 5$ levels after axotomy contrast with the lack of an effect on $\alpha 5$ after target tissue removal before synaptogenesis, which avoids direct damage to CG neurons (Levey et al., 1995). This 

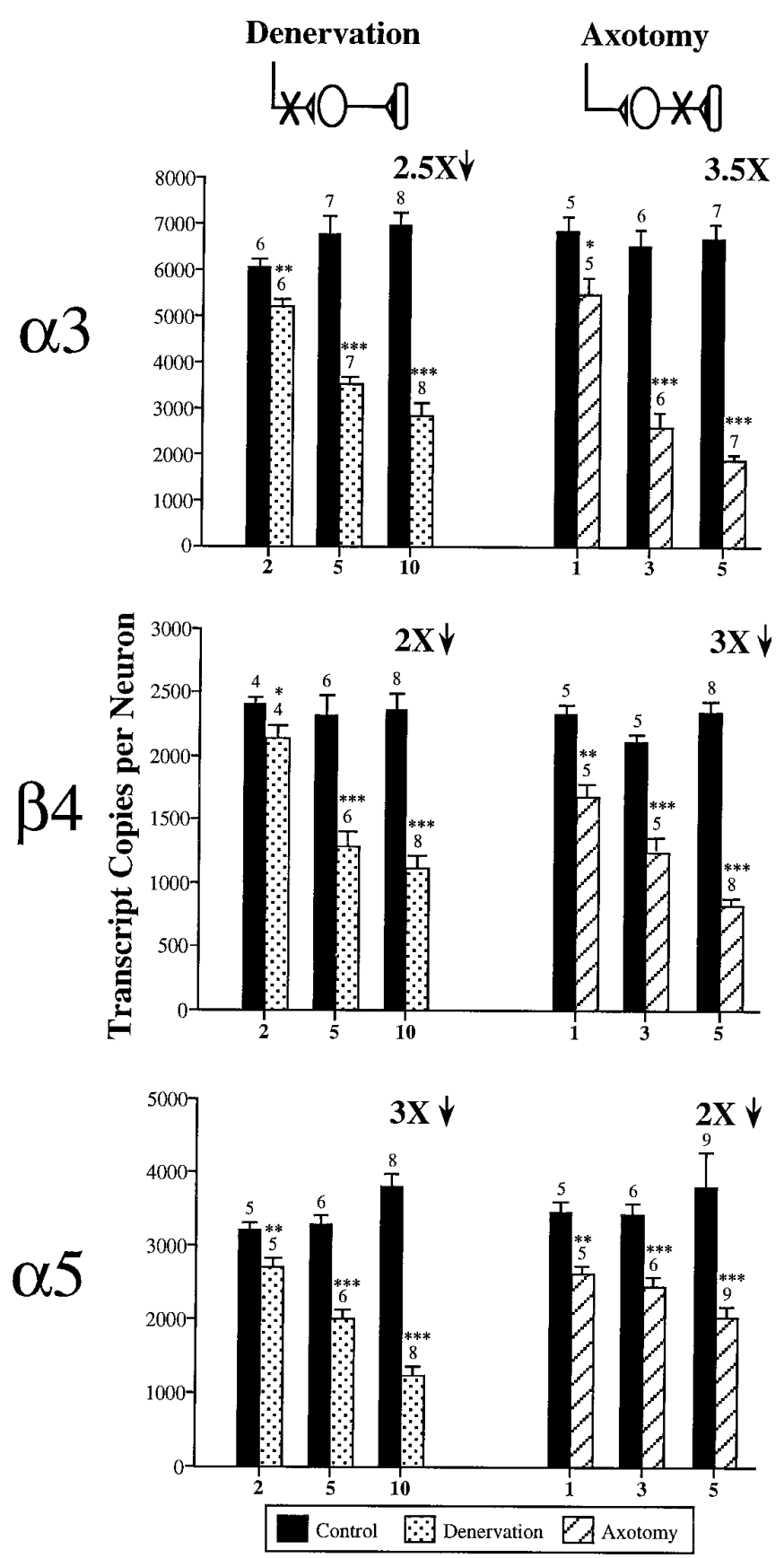

Days after Operation

Figure 2. AChR $\alpha 3, \beta 4$, and $\alpha 5$ subunit mRNA levels rapidly decline after surgical disruption of synaptic connections in mature CG neurons. AChR subunit transcript levels were quantified in individual CGs after unilateral surgical transection of the preganglionic nerve (denervation) or postganglionic connections with target tissues (axotomy) in newly hatched chicks. Denervated CGs (dotted bars) and axotomized CGs (lined bars) were paired with the contralateral control CG (solid bars) from the same animal, sampled at the indicated times, and assayed using RT-PCR with known concentrations of mutated AChR cRNA internal standard. Data are expressed as the number of transcript copies per neuron to account for decreases in neuron number observed after axotomy but not denervation (see Table 1). Results represent the mean \pm SEM. The number of ganglia assayed is shown above each bar. Declines in $\alpha 3, \beta 4$, and $\alpha 5$ mRNA levels range from 2 -fold to 3.5 -fold by $10 \mathrm{~d}$ after denervation and $5 \mathrm{~d}$ after axotomy, compared with contralateral control neuron values. Asterisks, Statistically significant differences based on the Student's two-sided $t$ test: ${ }^{*} p<0.05 ;{ }^{* *} p<0.01 ; * * * p<0.001$. observation suggests a developmental change in the regulatory response to the target tissue after synapse formation. However, it also raises the important question as to whether declines in AChR mRNA levels after axotomy represent a general injury response or specific regulation attributable to the loss of a target-derived signal.

Reductions in AChR subunit transcript levels after axotomy and denervation appear to be specific. The number of transcript copies per neuron encoding $\mathrm{c} \beta 4$-tubulin, a neuron-specific form of $\beta$-tubulin (Sullivan et al., 1986), are not altered over the same time course by either experimental manipulation (data not shown). Similarly, cytoplasmic $\beta$-actin mRNA levels are not detectably affected after axotomy (Boyd et al., 1988).

\section{Decreases in AChR mRNA levels after axotomy represent specific regulation and not merely a response to axonal injury}

To establish further whether declines in AChR mRNA levels in axotomized neurons result from specific regulation and not axonal injury, localized colchicine application to $\mathrm{CG}$ postganglionic nerves was used to mimic the effects of axotomy without disturbing axonal integrity (Pilar and Landmesser, 1972). Colchicine treatment blocks fast axonal transport (Karlsson and Sjostrand, 1969; Davis, 1990). Similar to axotomy, colchicine causes a characteristic chromatolytic reaction, which is likely attributable to the disruption of rapid protein transport and includes fragmentation and dispersal of the Nissl substance (Pilar and Landmesser, 1972). A small cotton pellet containing a dried 5\% colchicine solution was applied briefly to the postganglionic nerves on one side only at 1.5 weeks after hatching, which resulted in greater survival than manipulating the chicks at the earlier ages used previously (Pilar and Landmesser, 1972) (see Materials and Methods). For comparison, CGs were also axotomized at this later age. Serial paraffin sections were used to establish the proportion of ciliary neurons undergoing chromatolysis after colchicine treatment and axotomy. Choroid neurons were not evaluated, because they do not undergo a typical chromatolytic reaction after axotomy; there is no apparent change in the normally dispersed distribution of individual rough endoplasmic reticulum cisternae in the cytoplasm (Pilar and Landmesser, 1972). In control ganglia, 95\% of the ciliary neurons have a dense perinuclear ring of Nissl substance that is visible after toluidine blue staining (Fig. 3). After colchicine treatment, $\sim 50 \%$ of the ciliary neurons have a typical chromatolytic staining pattern indicative of the dispersal of Nissl substance, whereas the remaining ciliary neurons appear normal at $5 \mathrm{~d}$. After axotomy, all of the ciliary neurons have a characteristic chromatolytic appearance within $5 \mathrm{~d}$. Chromatolysis is not an indication of cell death (Bodian and Mellors, 1945). No change in neuron number was observed up to $15 \mathrm{~d}$ after colchicine treatment (Table 1). Moreover, there is no change in the proportion of chromatolytic ciliary neurons at $5 \mathrm{~d}$ compared with $15 \mathrm{~d}$ after colchicine exposure (Fig. 3). There is a $37 \%$ reduction in total neuron number at $5 \mathrm{~d}$ after axotomy, but this is much lower than the number of chromatolytic ciliary neurons, 82 and $98 \%$, seen at 3 and $5 \mathrm{~d}$ after axotomy, respectively (Table 1, Fig. 3). Thus, colchicine treatment and axotomy cause similar morphological changes in the neurons. The difference in the percentage of the affected neurons may reflect a lack of penetration of colchicine at adequate concentrations into all axons of the postganglionic nerves.

AChR subunit mRNA levels are reduced to a comparable extent after colchicine exposure and axotomy (Fig. 4). Colchicine causes twofold and 1.5-fold declines in $\alpha 3$ and $\alpha 5$ mRNA levels, respectively, compared with contralateral control neuron values 


\section{A. Neuronal Morphology}

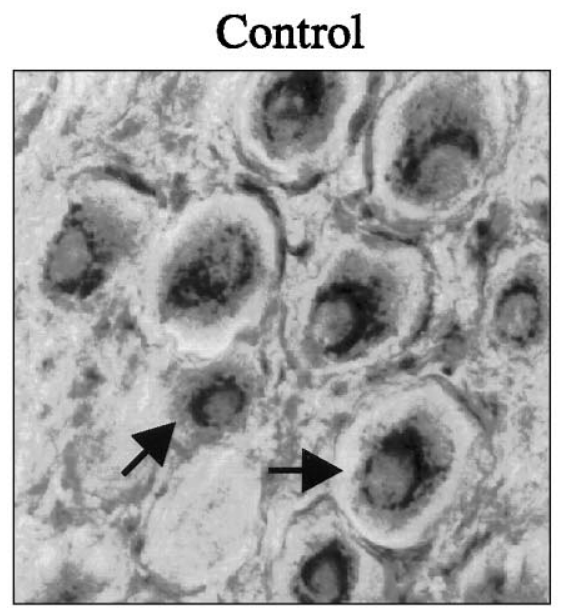

\section{Days after Colchicine Treatment}

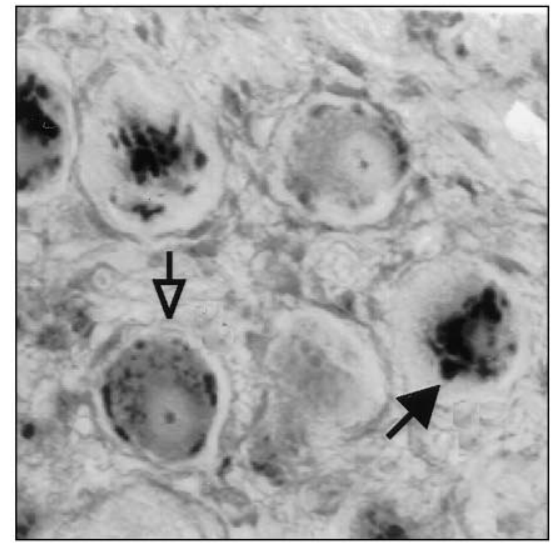

5 Days after Axotomy

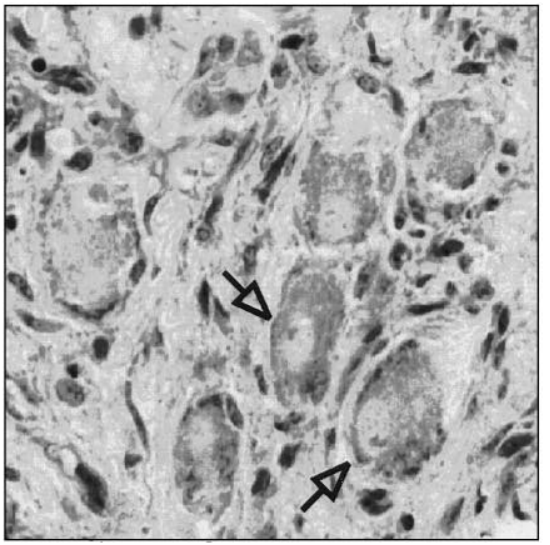

\section{B. Percentage of Neurons per Ganglion Undergoing Chromatolysis}

\begin{tabular}{|l|c|}
\hline Control & $5 \% \pm 3 \%$ \\
\hline Colchicine D5 & $51 \% \pm 12 \%$ \\
Colchicine D15 & $43 \% \pm 11 \%$ \\
\hline Axotomy D1 & $11 \% \pm 4 \%$ \\
Axotomy D3 & $82 \% \pm 7 \%$ \\
Axotomy D5 & $\mathbf{9 8 \%} \pm 2 \%$ \\
\hline
\end{tabular}

Figure 3. Brief colchicine application to CG postganglionic nerves causes a typical chromatolytic reaction in ciliary neurons similar to axotomy. Unilateral colchicine treatment of CG postganglionic nerves was used to block fast axonal transport without disturbing axonal integrity (for details, see text and Material and Methods). Ciliary neuron morphology was compared in colchicine-treated, axotomized, and contralateral control CGs at $5 \mathrm{~d}$ after the manipulation. CGs were fixed, embedded in paraffin, serially sectioned, stained with toluidine blue, and examined by bright-field microscopy. $A$, Micrographs demonstrating the typical appearance of neurons in contralateral control, colchicine-treated, and axotomized CGs. Ciliary neurons contain a dense perinuclear ring of Nissl substance (closed arrows) in control CGs. Colchicine treatment causes a characteristic chromatolytic reaction, including dispersal of the Nissl throughout the cytoplasm (open arrows), in some ciliary neurons, whereas others appear normal (closed arrows). After axotomy, ciliary neurons have a typical chromatolytic staining pattern (open arrows). B. The proportion of ciliary neurons in colchicine-treated, axotomized, and contralateral control CGs undergoing chromatolysis at the indicated times after treatment or surgery. Each value represents the mean \pm SEM of two to three ganglia that were serially sectioned and counted separately. Colchicine treatment causes approximately one-half of the ciliary neurons to exhibit a typical chromatolytic staining pattern resembling the morphological changes seen after axotomy.

after 5 d. Similarly, axotomy causes 3.5-fold and twofold reductions in $\alpha 3$ and $\alpha 5$ transcript levels, respectively, within $5 \mathrm{~d}$; these values are identical to the decreases seen when axotomy is performed on younger chicks (Fig. 2). In total, these results demonstrate that declines in AChR subunit transcript levels after axotomy represent, at least in part, specific regulation by retrograde signals from the target tissue.

\section{DISCUSSION}

Major findings reported here are that $\operatorname{AChR} \alpha 3, \beta 4$, and $\alpha 5$ subunit transcript levels increase dramatically during synaptogenesis and then level off, and the maintenance of these mRNA levels requires the continued presence of both innervation and target tissue interactions in mature CG neurons in situ. In addition, there is a developmental change in the regulatory effect of the target tissue on $\alpha 5$ mRNA expression. Removing the target tissue before synaptogenesis causes no change in $\alpha 5 \mathrm{mRNA}$ levels in the CG, whereas $\alpha 3$ and $\beta 4$ mRNA levels are reduced relative to contralateral control neuron values (Levey et al., 1995). In contrast, $\alpha 5, \alpha 3$, and $\beta 4$ transcript levels are all specifically decreased when target tissue interactions are disrupted after synapse formation by either axotomy or colchicine treatment of the postganglionic nerve, which blocks fast transport without disturbing axonal integrity. 


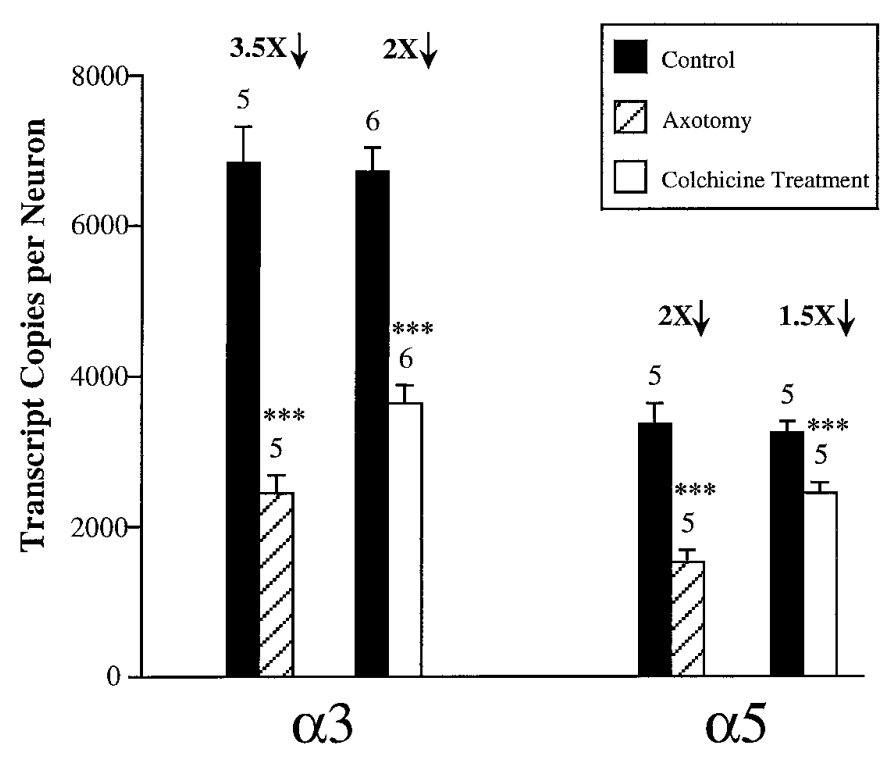

Figure 4. AChR subunit mRNA levels are reduced to a similar extent after colchicine treatment and axotomy. AChR $\alpha 3$ and $\alpha 5$ transcript levels are compared in CGs after colchicine treatment of the postganglionic nerves at 1.5 weeks posthatch (open bars), CGs axotomized at this later age (lined bars), and contralateral control CGs (solid bars), all sampled at $5 \mathrm{~d}$ after the manipulation. Values represent the mean $\pm \mathrm{SEM}$. The number of ganglia assayed is shown above each bar. Similar declines in $\alpha 3$ and $\alpha 5$ transcript copies per neuron after colchicine treatment and axotomy, relative to contralateral control neuron levels, demonstrate that retrograde signals from the target tissue specifically regulate $\mathrm{AChR}$ expression in mature CG neurons. Asterisks, Statistically significant differences based on the Student's two-sided $t$ test: $* * * p<0.001$.

This developmentally acquired ability of target tissues to regulate $\alpha 5$ mRNA levels after synaptogenesis suggests a dependence on peripheral synapse formation. Contact between the nerve and muscle may be required for activity of the signal, or innervation may induce its expression in the target tissue. This regulatory change is particularly interesting, because the $\alpha 5$ subunit may be necessary for the formation of high-conductance AChR complexes. In vitro expression studies demonstrate that $\alpha 5$ does not form functional channels when co-expressed with either an $\alpha$-type or a $\beta$-type subunit (Couturier et al., 1990). However, AChRs containing $\alpha 5$ together with another $\alpha$-type and $\beta$-type subunit have a higher conductance than AChRs formed by that $\alpha$ and $\beta$ subunit in the absence of $\alpha 5$ (Ramirez-Latorre et al., 1996). The relative abundance of high-conductance AChRs increases on CG neurons during synapse formation and maturation (Margiotta and Gurantz, 1989). Levels of $\alpha 5$ transcripts also increase relative to the more abundant $\alpha 3$ during this period, causing a shift from fivefold to only twofold higher $\alpha 3$ (Fig. 1) and, therefore, suggesting that a greater number of AChRs contain $\alpha 5, \alpha 3$, and $\beta 4$ subunits in mature CG neurons. Overall, innervation and target tissues both provide regulatory signals that induce and subsequently maintain mature levels of AChR subunit transcripts, and these regulatory events are likely to result in optimal levels of AChR expression and synaptic activity in CG neurons in situ.

\section{Cell-cell interactions cause similar regulatory changes in AChR mRNA and protein levels}

Regulatory changes in AChR mRNA levels correlate well with AChR protein levels, suggesting that the regulation of AChR expression by cell-cell interactions occurs at the level of gene transcription. However, it is also possible that cell-cell interac- tions influence AChR mRNA stability. AChRs in the late stage embryonic CG (E17-E18) all contain both $\alpha 3$ and $\beta 4$ subunits, whereas a subpopulation, or possibly all, also contain $\alpha 5$ (Vernallis et al.,. 1993; Conroy and Berg, 1995). AChR subunit transcript levels appear to be rate-limiting for $\mathrm{AChR}$ expression in $\mathrm{CG}$ neurons in vivo.

During normal development, $\alpha 3, \beta 4$, and $\alpha 5$ mRNA levels per neuron increase 7-fold, 5-fold, and 16-fold, respectively, during synapse formation and are then maintained, again with $\alpha 3$ mRNA levels being at least twofold more abundant than $\alpha 5$ and $\beta 4$ at all ages examined (see also Corriveau and Berg, 1993). AChR protein levels per neuron follow a similar pattern, increasing 12-fold during synaptogenesis (Smith et al., 1985). Similarly, declines in $\alpha 3, \beta 4$, and $\alpha 5$ mRNA levels range from twofold to 3.5 -fold after denervation or axotomy and resemble in extent the threefold declines in AChR protein levels seen $10 \mathrm{~d}$ after denervation (Jacob and Berg, 1987; Boyd et al., 1988). In comparison, axotomy results in 10-fold declines in both the total number of AChRs (surface plus internal) and the whole-cell ACh induced response within 5 d (Brenner and Martin, 1976; Jacob and Berg, 1987; Boyd et al., 1988; McEachern et al., 1989). Denervation causes no detectable change in ACh response (McEachern et al., 1989). Most of the loss of AChRs occurs in the large intracellular pool in denervated neurons (Jacob and Berg, 1988). Declines in AChR mRNA and protein levels after axotomy represent specific regulation and not merely an injury response. After axotomy, there is no significant change in $\mathrm{c} \beta 4$-tubulin or $\beta$-actin mRNA levels, membrane electrical properties, mean diameters of neuronal somas or nuclei, or the GABA sensitivity of CG neurons, whereas denervation causes a twofold reduction in the GABA response (Brenner and Johnson, 1976; Brenner and Martin, 1976; Jacob and Berg, 1987; Boyd et al., 1988; McEachern et al., 1989). No gross degenerative changes are observed in surviving neurons of axotomized ganglia at the light or electron microscopic level (Jacob and Berg, 1987, 1988) (this present study). Moreover, colchicine mimics the effects of axotomy on AChR mRNA levels. Colchicine does not injure axonal membranes or myelin sheaths; colchicine applied to $\mathrm{CG}$ postganglionic nerves in a similar manner, but at a two- to fourfold higher concentration, compared with that used here, had no affect on either impulse conduction through the site of application or macroscopic appearance of the nerves (Pilar and Landmesser, 1972). Further, the inhibition of fast axonal transport by colchicine is reversible (Perisic and Cuenod, 1972; Davis, 1990). All together, these results suggest that the CG target tissues provide regulatory factors that directly or indirectly influence AChR mRNA and protein levels in the innervating neurons. Greater reductions in both internal and surface AChR protein levels after axotomy, compared with denervation, correlate with significantly lower $\alpha 3$ and $\beta 4$ mRNA levels (Fig. 5) (Student's $t$ test). In contrast, $\alpha 5$ mRNA levels are reduced to a similar extent at matched ages after these two surgeries. Previously, changes in the whole-cell ACh response were also observed to correlate with $\alpha 3$ and possibly $\beta 4$, but not $\alpha 5$, mRNA levels in CG neurons deprived of target tissues before synaptogenesis (Levey et al., 1995). A correlation between $\alpha 3$ mRNA levels and ACh current densities has also been observed in chick and rat sympathetic neurons in vivo and in vitro (Listerud et al., 1991; Yu et al., 1993; Mandelzys et al., 1994; De Koninck and Cooper, 1995). Finally, additional causes of the large declines in AChR protein levels after axotomy may include alterations in posttranscriptional events, such as translational efficiency, subunit assembly, transport, insertion and/or metabolic stability of 


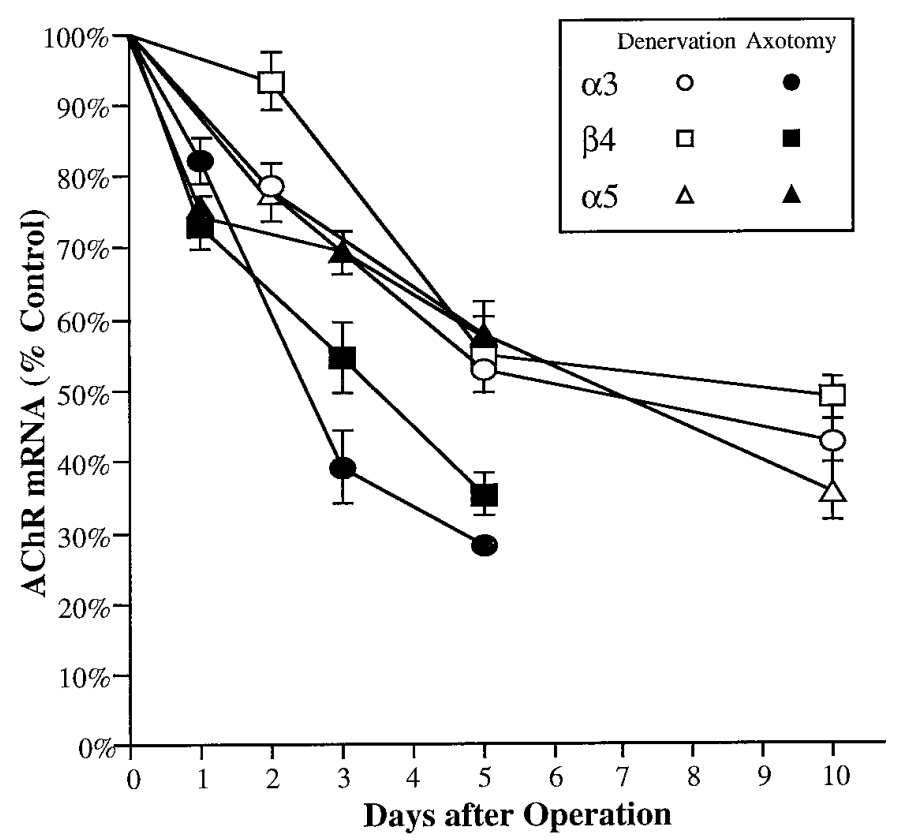

Figure 5. Summary of the declines in $\operatorname{AChR} \alpha 3, \beta 4$, and $\alpha 5$ subunit mRNA levels per neuron over time after denervation and axotomy. The number of $\alpha 3, \beta 4$, and $\alpha 5$ transcript copies per neuron after axotomy (solid symbols) or denervation (open symbols) is presented as a percent of those present in contralateral control neurons. Values represent the mean \pm SEM and were calculated from the data presented in Figure 2. Reductions in $\alpha 3$ and $\beta 4$ mRNA levels are significantly greater after axotomy compared with denervation (Student's $t$ test). In contrast, $\alpha 5$ mRNA levels are decreased to a similar extent at matched ages after these two surgeries.

AChRs. Studies of many different neuronal genes demonstrate that, in general, greater changes in the level of expression occur in target-deprived CGs, compared with input-deprived CGs, suggesting that the target tissue is the more important regulatory influence, controlling the differentiation state of its innervating neurons (Levey et al., 1995; Thomas et al., 1995) (M. Jacob and O. Ikonomov, unpublished observations).

\section{Regulatory effects of innervation and target tissue interactions change with maturation}

During synapse formation, innervation and target tissues have unique, as well as redundant, inductive effects on AChR subunit mRNA levels (Levey et al., 1995). $\alpha 3$ and $\beta 4$ mRNA levels are increased by both presynaptic inputs and target tissues. In contrast, $\alpha 5$ is increased by innervation, whereas target tissue interactions have little, if any, effect. After synaptogenesis, maintenance of all three transcript levels requires both presynaptic inputs and target tissue interactions (Fig. 5). Thus, innervation and target tissues have similar regulatory effects at these later stages. The ability of the target tissues to regulate $\alpha 5$ mRNA levels after, but not before, synaptogenesis may be attributable to either a contact-mediated factor on the surface of the target tissues, or innervation may induce the expression or release of a new target tissue factor. In comparison, electrical activity does not appear to regulate $\mathrm{AChR}$ expression in neurons as it does in multinucleated skeletal muscle (Role, 1988; Hieber et al., 1992; De Koninck and Cooper, 1995).

Precedence exists for reciprocal regulatory interactions at the peripheral synapse influencing development of the mature neurotransmitter phenotype in neurons in vivo. Specifically, innervation of sweat glands in the rat footpad by noradrenergic sympa- thetic neurons induces production of a target-derived cholinergic differentiation activity (Habecker and Landis, 1994; Habecker et al., 1995). This activity in turn induces the afferent neurons to switch from a noradrenergic to cholinergic phenotype. This change in neurotransmitter properties is critical for functional maturation of the sweat gland, because ACh induces and maintains the secretory response through muscarinic receptor activation (Grant et al., 1995). Thus, developmentally regulated reciprocal interactions between the target tissue and its innervating neurons are responsible for functional maturation of the circuit.

Similarly, developmental changes in the CG target muscle tissue correlate with increasing innervation. These alterations include a transition from smooth muscle to predominantly striated muscle in the iris and the expression of factors, such as activin A, follistatin and ciliary neurotrophic factor (CNTF), that influence survival and differentiation of innervating CG neurons (Pilar et al., 1987; Darland et al., 1995; Finn and Nishi, 1996). The relationship of these developmental events to maturational changes in the regulatory effects of the target tissue on AChR expression are presently unknown. The specific factors that mediate the regulatory effects of target tissues and presynaptic input on AChR expression and the molecular mechanisms of their action remain to be determined. Moreover, the present results suggest that the target tissue provides multiple factors, with the factor that influences $\alpha 5$ mRNA levels differing from that (those) that affects $\alpha 3$ and $\beta 4$ expression. Interestingly, genes encoding these subunits are clustered in the avian genome; $\beta 4$ lies $5^{\prime}$ of $\alpha 3$ and is transcribed from the same DNA strand, whereas $\alpha 5$ lies $3^{\prime}$ of $\alpha 3$ and is transcribed from the opposite DNA strand (Couturier et al., 1990).

In summary, innervation and target tissue interactions both play an essential role in the induction and maintenance of $\mathrm{AChR} \alpha 3$, $\beta 4$, and $\alpha 5$ subunit transcript levels in CG neurons in situ. Thus, neurons continually depend on signals from their pre- and postsynaptic tissues to accomplish mature levels of AChR subunit expression and optimal functioning of that neuronal circuit.

\section{REFERENCES}

Abercrombie M (1946) Estimation of nuclear population from microtome sections. Anat Rec 94:239-247.

Anand R, Conroy WG, Schoepfer R, Whiting P, Lindstrom J (1991) Neuronal nicotinic acetylcholine receptors expressed in Xenopus oocytes have a pentameric quaternary structure. J Biol Chem 266:11192-11198.

Arenella LS, Oliva JM, Jacob MH (1993) Reduced levels of acetylcholine receptor expression in chick ciliary ganglion neurons developing in the absence of innervation. J Neurosci 13:4525-4537.

Bodian D, Mellors RC (1945) The regenerative cycle of motoneurons, with special reference to phosphatase activity. J Exp Med 81:469-488.

Boyd RT, Jacob MH, Couturier S, Ballivet M, Berg DK (1988) Expression and regulation of neuronal acetylcholine receptor mRNA in chick ciliary ganglia. Neuron 1:495-502.

Brenner HR, Johnson EW (1976) Physiological and morphological effects of post-ganglionic axotomy on presynaptic nerve terminals. J Physiol (Lond) 260:143-158.

Brenner HR, Martin AR (1976) Reduction in acetylcholine sensitivity of axotomized ciliary ganglion cells. J Physiol (Lond) 260:159-175.

Conroy WG, Berg DK (1995) Neurons can maintain multiple classes of nicotinic acetylcholine receptors distinguished by different subunit compositions. J Biol Chem 270:4424-4431.

Cooper E, Couturier S, Ballivet M (1991) Pentameric structure and subunit stoichiometry of a neuronal nicotinic acetylcholine receptor. Nature 350:235-238.

Corriveau RA, Berg DK (1993) Coexpression of multiple acetylcholine receptor genes in neurons: quantification of transcripts during development. J Neurosci 13:2662-2671.

Couturier S, Erkman L, Valera S, Rungger D, Bertrand S, Boulter J, Ballivet M, Bertrand D (1990) $\alpha 5, \alpha 3$, and non- $\alpha 3$ : three clustered 
avian genes encoding neuronal nicotinic acetylcholine receptor-related subunits. J Biol Chem 265:17560-17567.

Darland DC, Link BA, Nishi R (1995) Activin A and follistatin expression in developing targets of ciliary ganglion neurons suggests a role in regulating neurotransmitter phenotype. Neuron 15:857-866.

Davis RE (1990) Effect of optic nerve lesions and intraocular colchicine on cell proliferation in the germinal zone of the optic tectum and in the torus longitudinalis in the goldfish. Brain Res 512:46-53.

De Koninck P, Cooper E (1995) Differential regulation of neuronal nicotinic ACh receptor subunit genes in cultured neonatal rat sympathetic neurons: specific induction of $\alpha 7$ by membrane depolarization through a $\mathrm{Ca}^{2+} /$ calmodulin-dependent kinase pathway. J Neurosci 15:7966-7978.

Dourado MM, Brumwell C, Wisgirda ME, Jacob MH, Dryer SE (1994) Target tissues and innervation regulate the characteristics of $\mathrm{K}^{+}$currents in chick ciliary ganglion neurons developing in situ. J Neurosci 14:3156-3165.

Feramisco JR, Smart JE, Burridge K, Helfman DM, Thomas GP (1982) Co-existence of vinculin and a vinculin-like protein of higher molecular weight in smooth muscle. J Biol Chem 257:11024-11031.

Finn TP, Nishi R (1996) Expression of a chicken ciliary neurotrophic factor in targets of ciliary ganglion neurons during and after the celldeath phase. J Comp Neurol 366:559-571.

Furber S, Oppenheim RW, Prevette D (1987) Naturally occurring neuron death in the ciliary ganglion of the chick embryo following removal of preganglionic input: evidence for the role of afferents in ganglion cell survival. J Neurosci 7:1816-1832.

Grant MP, Francis NJ, Landis SC (1995) The role of acetylcholine in regulating secretory responsiveness in rat sweat glands. Mol Cell Neurosci 6:32-42.

Habecker BA, Landis SC (1994) Noradrenergic regulation of cholinergic differentiation. Science 264:1602-1604.

Habecker BA, Tresser SJ, Rao MS, Landis SC (1995) Production of sweat gland cholinergic differentiation factor depends on innervation. Dev Biol 167:307-316.

Hamburger V, Hamilton HL (1951) A series of normal stages in the development of the chick embryo. J Morphol 88:49-82.

Hieber V, Agranoff BW, Goldman D (1992) Target-dependent regulation of retinal nicotinic acetylcholine receptor and tubulin RNAs during optic nerve regeneration in goldfish. J Neurochem 58:1009-1015.

Jacob MH (1991) Acetylcholine receptor expression in developing chick ciliary ganglion neurons. J Neurosci 11:1701-1712.

Jacob MH, Berg DK (1987) Effects of preganglionic denervation and postganglionic axotomy on acetylcholine receptors in the chick ciliary ganglion. J Cell Biol 105:1847-1854.

Jacob MH, Berg DK (1988) The distribution of acetylcholine receptors in chick ciliary ganglion neurons following disruption of ganglionic connections. J Neurosci 8:3838-3849.

Karlsson J-O, Sjostrand J (1969) The effect of colchicine on the axonal transport of protein in the optic nerve and tract of the rabbit. Brain Res 13:617-619.

Landmesser L, Pilar G (1972) The onset and development of transmission in the chick ciliary ganglion. J Physiol (Lond) 222:691-713.

Landmesser L, Pilar G (1974a) Synapse formation during embryogenesis on ganglion cells lacking a periphery. J Physiol (Lond) 241:715-736.

Landmesser L, Pilar G (1974b) Synaptic transmission and cell death during normal ganglionic development. J Physiol (Lond) 241:737-749.
Levey MS, Brumwell CL, Dryer SE, Jacob MH (1995) Innervation and target tissue interactions differentially regulate acetylcholine receptor subunit mRNA levels in developing neurons in situ. Neuron 14:153-162.

Listerud M, Brussaard AB, Devay P, Colman DR, Role LW (1991) Functional contribution of neuronal AChR subunits revealed by antisense oligonucleotides. Science 254:1518-1521.

Mandelzys A, Pie B, Deneris ES, Cooper E (1994) The developmental increase in ACh current densities on rat sympathetic neurons correlates with changes in nicotinic ACh receptor $\alpha$-subunit gene expression and occurs independent of innervation. J Neurosci 14:2357-2364.

Margiotta JF, Gurantz D (1989) Changes in the number, function, and regulation of nicotinic acetylcholine receptors during neuronal development. Dev Biol 135:326-339.

Martin AR, Pilar G (1963a) Dual mode of synaptic transmission in the avian ciliary ganglion. J Physiol (Lond) 168:443-463.

Martin AR, Pilar G (1963b) Transmission through the ciliary ganglion of the chick. J Physiol (Lond) 168:464-475.

McEachern AE, Jacob MH, Berg DK (1989) Differential effects of nerve transection on the $\mathrm{ACh}$ and GABA receptors of chick ciliary ganglion neurons. J Neurosci 9:3899-3907.

Meriney SD, Pilar G (1987) Cholinergic innervation of the smooth muscle cells in the choroid coat of the chick eye and its development. J Neurosci 7:3827-3839.

Perisic M, Cuenod M (1972) Synaptic transmission depressed by colchicine blockade of axoplasmic flow. Science 175:1140-1142.

Pilar G, Landmesser L (1972) Axotomy mimicked by localized colchicine application. Science 177:1116-1118.

Pilar G, Nunez R, McLennan IS, Meriney SD (1987) Muscarinic and nicotinic synaptic activation of the developing chicken iris. J Neurosci 7:3813-3826.

Ramirez-Latorre J, Yu CR, Qu X, Perin F, Karlin A, Role L (1996) Functional contributions of $\alpha 5$ subunit to neuronal acetylcholine receptor channels. Nature 380:347-351.

Role LW (1988) Neural regulation of acetylcholine sensitivity in embryonic sympathetic neurons. Proc Natl Acad Sci USA 85:2825-2829.

Smith MA, Stollberg J, Lindstrom JM, Berg DK (1985) Characterization of a component in chick ciliary ganglia that cross-reacts with monoclonal antibodies to muscle and electric organ acetylcholine receptor. J Neurosci 5:2726-2731.

Sullivan KF, Havercroft JC, Machlin PS, Cleveland DW (1986) Sequence and expression of the chicken $\beta 5$ and $\beta 4$-tubulin genes define a pair of divergent $\beta$-tubulins with complementary patterns of expression. Mol Cell Biol 6:4409-4418.

Thomas WS, Jacob MH, O'Dowd DK, Smith MA (1995) Agrin gene expression in ciliary ganglion neurons following preganglionic denervation and postganglionic axotomy. Dev Biol 168:662-669.

Vernallis AB, Conroy WG, Berg DK (1993) Neurons assemble acetylcholine receptors with as many as three kinds of subunits while maintaining subunit segregation among receptor subtypes. Neuron 10:451-464.

Yu C, Brussaard AB, Yang X, Listerud M, Role LW (1993) Uptake of antisense oligonucleotides and functional block of acetylcholine receptor subunit gene expression in primary embryonic neurons. Dev Genet $14: 296-304$. 